\title{
Is there still a role for ultrasound in trauma?
}

\author{
Jamie Moran ${ }^{*}$, Tim Harris, Jeremy Purdell-Lewis \\ From London Trauma Conference 2014 \\ London, UK. 9-12 December 2014
}

\section{Background}

The UK College of Emergency Medicine recommends that level 1 ultrasound competency is a basic standard for EM doctors and is now mandatory for career progression. Focused Assessment with Sonography in Trauma to include the detection of pleural fluid and pneumothorax (the Extended-FAST scan) forms part of this competency. We compare the diagnostic accuracy of E-FAST with the "gold standard" of CT or operative intervention. Trauma team leaders were asked to evaluate point-of-care ultrasound in their decision-making and patient management.

\section{Methods}

\section{Setting}

Royal London Hospital. The Major Trauma Centre for North East London and base for London's Air Ambulance. Approximately 2500 adult trauma cases seen per year.

\section{Study design}

Prospective observational study, comprising convenience sample of adult major trauma presenting to Royal London between October 2012-March 2013 leading to activation of a "trauma call".

\section{Primary outcome}

To assess the diagnostic accuracy of E-FAST in the detection of haemorrhage (free fluid) and pneumothorax in major trauma.

\section{Secondary outcome}

To assess the impact of E-FAST on trauma team leader's decision-making process in major trauma care.

\section{Reference Standard}

Free fluid or pneumothorax formally reported on CT or found at time of surgical intervention.

\footnotetext{
* Correspondence: james.moran@nhs.net

Emergency Department, Royal London Hospital Barts Health NHS Trust,
} London, UK and take full advantage of:

- Convenient online submission

- Thorough peer review

- No space constraints or color figure charges

- Immediate publication on acceptance

- Inclusion in PubMed, CAS, Scopus and Google Scholar

- Research which is freely available for redistribution 